\title{
Management Mode and Content Innovation of Chinese Internationalization Education in Countries Along "The Belt and Road"
}

\author{
Li Hou ${ }^{1}$ and Jianjun Kang ${ }^{1,2, *}$
}

\author{
${ }^{1}$ School of Foreign Languages, LiaoCheng University, LiaoCheng, ShanDong, 252059, China \\ ${ }^{2}$ Institute of Literature, Jiangxi Academy of Social Sciences, NanChang, Jiangxi,330077, China \\ *Corresponding author. Email: akanghao@126.com
}

\begin{abstract}
The countries and regions along "The Belt and Road" are increasingly involved in Chinese affairs, and are exposed to more and more Chinese economic and cultural content. Therefore, these countries have more and more demands for Chinese language learning. In the process of Chinese internationalization education, traditional management modes and teaching methods have been challenged and questioned in all aspects. The purpose of the work is to promote overseas teaching of Chinese literature, This study is aimed to improve teaching quality and teaching effect, the promotion of teaching Chinese to speakers of other languages cannot be separated from the support of traditional Chinese culture. As an emerging interdisciplinary subject, Chinese traditional culture provides content such as natural environment, mountain scenery, human geography, philosophical thinking, human-land relationship, human society, etc, which tends to become the knowledge points students are interested in during the process of teaching Chinese as a foreign language. Under the background of "Belt and Road", the breadth of teaching Chinese to speakers of other languages is expanding increasingly and the depth is expanding gradually as well.
\end{abstract}

Keywords: Management Mode; Content Innovation; Teaching Chinese to speakers of other languages; The

Belt and Road

\section{INTRODUCTION}

"The Belt and Road" is the road of economy and development. It will also become the road of culture and education. In the foreseeable future, the knowledge system of Chinese classical culture will play an important role in the promotion of teaching Chinese to speakers of other languages.As a large and complex education system, it is necessary to develop and build targeted management modes and innovate language teaching modes under the requirements of the "One Belt, One Road" strategy, making Chinese education one of the hottest foreign language training courses, and further expanding the learning enthusiasm and learning effectiveness of overseas Chinese learners.

Chinese traditional culture is the study of literary works and literary writers in different regions. Chinese classical culture provides content such as natural environment, mountain scenery, human geography, philosophical thinking, human-land relationship, human society, etc, which tends to become the knowledge points students are interested in during the process of teaching Chinese as a foreign language. Some excellent works will become the materials for both students and teachers. These works enable students to learn about China's traditional culture, geographical common sense, mountains and rivers and local customs. In turn, it plays a very important role for overseas friends to understand China.

\section{THERE IS A GOOD HISTORICAL BASIS FOR THE PROMOTION OF CHINESE IN THE COUNTRIES ALONG THE "THE BELT AND ROAD"}

Chinese traditional culture based on the theory of humanland relationship, and studying the multi-level dialectical relationship between literature and geography. The regions of different cultures and the literary of different regions have enriched the traditional Chinese culture.

Language and writing not only bears the outward representation of culture, but also functions as the culture carrier, so that culture can be passed down from generation to generation in the process of gradually increasing its connotation and extension. As far as the traditional Confucian thinking is concerned, the concept of life "being in the world and out of the world" and the concept of education "fair education for all" and "individualized education", generally accepted by Chinese people, has a long history, at least dating back to the Spring and Autumn Period. However, today people still understand them and 
apply them to social life because they are the carrier of language and words. There are two main ways in which language and words carry culture. One is handing down orally, the other is resorting to writing.

We should see that the starting point and the foothold of geospatial research in literary works should be geospatial + literary works. The author's writing theme should be regulated by texts. Emphasis should be attached on that the literary standpoint is the text itself rather than others. The formation of geospatial spaces, the basic forms of existence and patterns of manifestation in literary works should be explored. In general, with ecological protection and natural environment as the writing theme and human environment and national society as the writing content of literary works, it is easy to enrich the content carried by Chinese traditional culture.

\subsection{The promotion of Chinese in the countries along "The Belt and Road" has a good historical foundation}

The language and characters of human ancestors were originally a calling system, and they were enclosed. They were nothing more than simple notes and carved marks. After diachronic development, they gradually turned into various symbolic languages and words and they are open, which is the result of natural selection. The use of language and words has enabled human culture to spread and develop. With language and words, members of different tribes and ethnic groups can talk to each other, exchange information, share food, and create complex tools and buildings. They can also effectively resolve differences of opinion and territorial disputes.

Chinese traditional culture takes the generation, distribution, change, dissemination of various literary phenomena and the spatial structure of human literary activities as the main content, and the study of human-land relationship as the starting point and the foothold. As the core of Chinese traditional culture theory, the study of human-land relationship has many levels of connotation:

1. "People" includes authors, readers and commentators, not only the producers of literary creation - writers, but the characters in the works created by writers, and also the consumers of literary creation - readers and commentators. 2. "the land" includes the real natural geographical environment, the human geography environment as the background and the literary space as the result: referring to the author's birthplace and the region of his literary activities and also the geographical background of the work content and the virtual regional scenes in the works. It also includes the geographical scope of the spread and relocation of works.

3 . The core of Chinese traditional culture is to concern with the interaction between man and earth and the way it presents in works[1].

\subsection{The management mode of Chinese internationalization education needs to be further adapted to the national conditions of the host country}

Language, characters, and especially characters, are presented through the tangible form of symbols and are accepted by everyone. People try to use these symbols to communicate. There are many ways of human communication, both in language and in written form, as well as in non-verbal and non-written forms. However, language and characters have absolute advantages in information exchange. Language and character can reflect a certain social development process and is also a sign of the stage of social development. For example, when people study the semantic field and specifically analyze the semantics of the words related to color or relatives, they can usually find that in a certain period of time, social value orientations and social systems are often closely related to the historical and political conditions at that time. In fact, it can also be found that many regular changes in language and writing result from the exchange, influence and adaptation of different cultures. People communicate mainly through language and words to address specific issues and events. When this kind of communication is affected by the changes of social development, the original vocabulary usage shows great incompatibility, so there will be two choices, making adaptation to survive; making no change to be washed out.

The growth of language and words has also led to the growth and prosperity of culture. For example, human beings disseminate production experience through language and words and spread and develop from generation to generation. Another example is, the occurrence of human cultural behavior is mostly based on language and words. Due to the development of language and writing, human thinking has also been consolidated and developed, including social politics, daily life, literary culture, and art fields, which have also been changed through language, literal communication, and communication.

\subsection{Content innovation of Chinese international education contributes to deep cultural integration and Chinese language promotion}

Different peoples and people living in different environments have different outlooks on life, world views and values as well as different views on reality because different languages and words are spoken. And each language and text makes reality a survival mode and a life scene that appears different in expression. Language and writing have unique merits in describing social activities, human emotions, and ideological conditions, and the reality of social economy is more likely to change language, words and thoughts. In other words, the 
influence of culture on language and words is far stronger than the influence of language and words on culture. The variation or differentiation of language and words is mostly due to the role of culture.

Although some ethnic groups speak the same language and words, they are influenced by various factors, such as geographical separation, political change, outbreak of war, economic prosperity or downturn, which may lead to the isolation of a group and make language and words, the writing of the voice, form and grammar, and so on, undergo subtle changes. This change has gradually increased over time. In the end, the two dialects, originally from the same language and text, will become two relatively independent languages and words.

This is a phenomenon of language and word differentiation caused by information isolation and information islands. In turn, frequent contacts between different ethnic groups, such as frequent economic and political exchanges, even negative factors such as war, often lead to language and textual fusion, vocabulary proximity and similarity, and even integration into an independent language. For example, loanwords come into being due to the long-term contact of two different languages and words.

\section{THE TEACHING AND DISSEMINATION OF CHINESE INTERNATIONALIZATION IS A NECESSITY FOR CULTURAL COMMUNICATION AND AN IMPORTANT MEASURE FOR THE CONSTRUCTION OF "THE BELT AND ROAD"}

In the context of the community of human destiny, the proposition of cultural integration is undoubtedly a positive promotion for the various cultures already on the planet. The traditional Chinese culture with a history of 5,000 years is one of the most vigorous and most abundant cultures. The world's call for "going out" of Chinese national studies is getting louder and louder, and the "going out" of Chinese national studies is also the increasingly rigid domestic demand for the world cultural stage.

\subsection{Teaching Chinese to speakers of other languages is very important for the spread of Chinese culture}

At the application level, culture has reverse and direct impact on the development and use of language and words. For example, when the country's original feudal monarchy changed its dynasty, the taboo words appeared on formal and informal occasions, destroying the writing structure and pronunciation of Chinese characters. This phenomenon of destroying cultural heritage for the so-called ritual law can also be found everywhere. For example, culture can influence speech. The standard voice of Mandarin in China is based on Beijing pronunciation. This is mainly because
Beijing is the capital of China and it is also the nation's political, economic and cultural center. And culture has an impact on words, voice, and grammar.

Henry Lefebvre believes that literary geography can provide abstract space, and that the logic of visualization takes precedence and vision surpasses other senses and predominates. Taste, touch and scent all give way to light, shadow and color[2]. Thus, it can be seen very intuitively that the common sense of Chinese traditional culture can make Chinese learners get a better first sense in term of senses, and then stimulate their interest in learning and consolidate the effect of learning.

With the opening up of modern China, Western culture is gradually absorbed by Chinese grammar. Chinese grammar and many expressions tend to be Europeanized, so the influence of modern science and modern culture on vocabulary is more obvious. With the changes in social life and social thoughts, vocabulary often changes accordingly. For example, with the demise of feudal society, many vocabulary with strong feudal colors, such as "Juren", "shutong" and "shiye", died with the end of the era. With the development of high-tech, many new will be produced, such as "nanotechnology", "genetically modified food", "Internet café", "nuclear magnetic resonance", "superconducting magnet", "genetically modified", "Xiongan New District", "BRIC countries", "artificial intelligence", "human destiny community", "email", "big data", "digital camera", "The Belt and Road", "cloning" and so on.

\section{2. "The Belt and Road" Construction Must Promote Teaching Chinese to speakers of other languages}

"The Belt and Road" is the link of the economy, the bridge of governments, and the channel of cultures. On one hand, "The Belt and Road" borrows the historical symbols and cultural connotations of the ancient Silk Road, and holds high the banner of peaceful development and sustainable development. On the other hand, through cooperation with the countries along the "The Belt and Road", we should actively develop partnership with other countries, such as economic cooperation, political mutual trust and cultural integration.

The social life and social revolution in contemporary China are making tremendous changes in this magical land, and many neologisms have emerged. Of course, many of the neologisms are only popular for a while, and they do not last long, so they are not likely to have an impact on culture, and they cannot become a part of culture. Only those words that penetrate deep into people's production and life and penetrate into the bottom of life will have real vitality, thus enriching the reality of language and writing, and then making cultural products vital. Only in this way can we achieve the benign interaction of common development and mutual promotion of language, writing and culture. 
Language and writing have profoundly influenced culture. For example, Buddhism has spread in China for nearly two thousand years and has a great influence on Chinese culture. Many Buddhist vocabulary words have been fully integrated into the vocabulary inherent in Chinese and become an integral part of Chinese. For example, freedom, insight, complicated legal case, homework, retribution, liberation, bodhi, merit, reincarnation, a blow and a shout, etc. all come from Buddhism. Buddhist words have even become idioms into the vocabulary system, which has made future generations feel that they are not Buddhist words, such as flowers cascading from the sky, slap in the face, act according to circumstances, the lightening before death, incredible and so on

\subsection{Teaching Chinese to speakers of other languages imperceptibly}

The most direct manifestation of the relationship among language, writing and culture is that language and words express people's world views, attitudes and values. Expressions being able to express people's views, attitudes and values of the world always can be found in various maxims, epigrams and proverbs. Individualism and collectivism are two different values. Proverbs all over the world express people's attitudes towards the relationship between individual and collective in different cultures. For example, the Mexican proverb: "Being a fool in a group is better than being a wise person." Turkish proverb: "A sheep that leaves the flock will be eaten by a wolf." Chinese proverb: "Two heads are better than one." American slang: "God helps those who help themselves". German proverb: "Mind one's own business." etc, are examples of colorful national cultures.

All Chinese speakers call the color of the snow "white", snow white, just like snow, and the meaning is easily received and copied. Two persons based on language and literature, may not know each other and see different snow, but their actual perception and color perception of snow is roughly the same. So people call this feeling "white" by coincidence. When referring to "white", according to people's life experience, there are pearl white, jazz white, smoky white, aconite white, ash white, ivory white, fish belly white. Pearl white and ivory white are the same white, however, one is the feeling of the fishermen on the beach, and the other is the feeling of the people in the tropical rain forest. Similarly, white is in various literary works, is mentioned as milky white, pure white, gray, white, dark white, rice white, pink white, silver white, black and white, tender white, milk white, blue white, scallion white, Jade white, fish belly white, grass white, snow white, etc. This meticulous division reflects the hierarchical sense of color and the sense of life experience.

\section{CHINESE CLASSICAL CULTURE PROVIDES THEORETICAL SUPPORT FOR THE INTERNATIONAL TEACHING AND COMMUNICATION OF CHINESE LANGUAGE, AND ALSO CONTRIBUTED TO THE PRACTICAL SAMPLE}

The cooperation situation of the industrial economy and the progress of globalization development along the "The Belt and Road" countries have supported the overall work of Chinese international communication. It has added a new impetus to the international exchange and dissemination of Chinese, and also given a new journey and connotation to the international exchange of Chinese. At the specific work level, it is necessary to further expand the service function and build a comprehensive platform integrating language teaching, cultural exchange, academic research and social services, focusing on service effectiveness and the validity of cultural communication. We should not only adhere to local conditions, flexibility and diversity, but also spare no effort to promote the characteristic development of Confucius Institutes in various countries. On the basis of highlighting the direction of teaching, research, cultural exchanges and vocational training, we should further integrate the advantages of teaching and service of Confucius Institutes and improve the comprehensive service level.

\subsection{Chinese traditional culture will certainly promote teaching Chinese to speakers of other languages}

As Professor Franco Moretti of Stanford University said, the space created by Chinese traditional culture in literary works is dominated by fictional space and poetic space, such as Paris in Balzac's works, colonial love in Africa, Austin's writing about Britain, etc, as well as the provincial library of Victorian Great Britain, or the spread of Don Quixote or the Buddenbrook Family in Europe, etc[3]. Geography knowledge is beneficial to the spread of culture.

As for the role of language and words in communication, the attitudes and values expressed by the maxims and proverbs in China, Japan, and the United States are different. Chinese and Japanese cultures emphasize the artistic conception of "Silence means more than words", which belongs to high-context culture and indirect-context culture. American culture attaches importance to direct language and written expression, which belongs to lowcontext culture and direct-context culture. For example, in China, "the gentleman is indifferent to words but sensitive to the line", in Japan "silence is gold", while in the United States "A squeaky wheels get the lubricant". Many maxims and proverbs from different cultures express different values, but there are situations in which similar values are expressed, indicating that people of different cultures share some common values. For example, there are maxims or 
proverbs in both Chinese and English that express the concepts of time and struggle. Chinese has "an inch of time is an inch of gold", while English has the corresponding "Time is money"; Chinese has "If you persevere, all things are possible" and English has the corresponding "Where there is a will, there is a way". One of the proverbs in Chinese is "Kill two hawks with one arrow", the corresponding one in English is "Kill two birds with one stone" and "Kill birds with one stone" in Russian.

\subsection{Chinese classical culture provides strong theoretical support for the international teaching and communication of Chinese Language}

In recent years, China has strongly encouraged and supported overseas Chinese to develop Chinese language education. For this reason, it has issued a number of policies and adopted various measures and organized various cultural activities at various levels, such as "China's Root-Finding Tour", "Chinese Cultural Paradise", "Chinese Cultural Contest", "Chinese Language Education - Huaxia Tour", and so on. This not only reflects the Party Central Committee's long-term vision of looking at the world and examining the country, but also reminds the Chinese people of the importance and urgency of accelerating the development of cultural reform. From top to bottom, a series of overall layouts for cultural reform and development, as well as major decision-making and specific deployments have been made. The activities have achieved good results and wide adaptability.

This activity of spreading excellent Chinese cultural treasures through overseas Chinese, especially ChineseAmerican teenagers, has a very good fit with the local people. It is also an emotional contact with the second and third generations of Chinese people. Relevant activities in form of exchange and visit performance have been carried out in dozens of countries, such as the United States, Canada, Britain, France, Germany, Australia, and so on. These "voluntary propagandists" of traditional Chinese culture fully demonstrate the charm of Chinese culture and the demeanor of the new generation of China with their exquisite talent and profound expression.

The demand for learning Chinese in the world is very strong and continues to grow. Among them, the practice in South Korea, Japan, and Thailand is very prominent, while the demand growth in European and American countries is also very rapid. According to Wang Zuyu and $\mathrm{Wu}$ Yinghui's "Report on Chinese International Communication Development (2011-2014)", as of 2014, there were 475 Confucius Institutes and 851 Confucius Classrooms in 126 countries and regions, with a total of 3.45 million registered students.

\subsection{Chinese classical culture contributes to a diversified practical sample for the international teaching and communication of Chinese Language}

Throughout the teaching of Chinese as a foreign language, it is necessary to participate in cultural and art festivals, coorganize seminars and cultural weeks, and use existing local platforms and their built workplaces and trained staff to promote Chinese culture and ideas and effectively display China's image of civilization, democracy, openness and progress. According to the work plan, by 2020, the total number of overseas Chinese cultural centers will reach more than 50 .

According to the requirements of the state's foreign cultural development strategy, the work of overseas Chinese cultural centers must focus on the comprehensive functions of "propaganda of National Conditions, ideological exchange, cultural exhibition, teaching and training, information service", plan and organize high-level, specialized cultural projects that conform to the appreciation habits of local audiences, and carry out allround cultural projects in big culture field to demonstrate Chinese culture and shape national image. Brand activities independently created by cultural centers according to local conditions have been widely welcomed by people from all walks of life and actively concerned by the news media. After several years of accumulation, some activities have already had a considerable impact on local society.

Chinese traditional culture has very rich content, such as geographical regions, cultural tomography, ethnic group separation, cultural mobility, etc, and has common knowledge in many disciplines such as literature and geography, anthropology, and ethnic, folklore system, history, Archaeology, which contribute to the teaching of Chinese as a foreign language.

Robert Taylor's study found that readers interpret the text of a seated place, such as when they read interesting stories, they use a broader form of imaginative geography, even want to take out maps, mark the location of a place, and establish a connection with the scene. They say, "Oh, that's it. Bartleby may have worked on Wall Street!" This is where Holden Caulfield in The Catcher in the Rye is likely to stay when he comes to New York![4] In this way, learners will be guided to pay attention to those works with the characteristics of Chinese traditional culture, which is also convenient for Chinese learners to understand and remember.

\section{CONCLUSION}

The ultimate goal of Chinese international education in the countries along "The Belt and Road" is to achieve the common development of politics, economy and culture in each country and region. In the process of cooperation, there will be certain problems, and the most common ones are language differences, cultural conflicts and psychological cognitive distance and so on. 
Chinese traditional culture is a new interdisciplinary or interdisciplinary research method which organically integrates literature and geography research, literaturebased, and focusing on literature space research. Its development direction is to grow into a relatively independent comprehensive discipline. The theory and criticism method of Chinese traditional culture will be of great academic significance to the study of Chinese literature in the world, and will also benefit the teaching of Chinese as a foreign language

In the actual teaching process, Chinese traditional culture not only enriches the research methods, but also provides rich research results, which can be used as a supplement to textbook knowledge in Chinese teaching, thus providing a good boosting power for Chinese teaching.

Therefore, strengthening the construction of language exchange and cultural cooperation will improve the effect of education management. At the same time, a good attitude toward dialogue and consultation, mutual help and mutual learning will help countries achieve the goal of mutual benefit and common progress.

Under the premise of management mode and content innovation, each country should also establish a good bilateral international image and reputation system to further increase the emphasis on Chinese language education, so as to promote the smooth implementation of "The Belt and Road" strategy on a global scale, and achieve universal benefits between countries.

\section{ACKNOWLEDGMENT}

Many thanks to the following fund projects:

1.Social science research fund project of Liaocheng University;

2. Postdoctoral research fund project of Jiangxi academy of social sciences-"literary geography and literary space"(NO.232197).

\section{REFERENCES}

[1] Cao Huimin, Geopoetics and the study of Chinese literature, Chinese literature, 2002, No. 1.(In Chinese)

[2] Henri Lefebvre, The Production of Space, Hoboken, New Jersey: Blackwell Publishing, 2011, p.286.

[3] Franco Moretti, Atlas of the European Novel 18001900, London: Verso, 1998, pp.3.70, 79-86.

[4]Robert T. Tally Jr.(ed.), Geocritical Explorations: Space, Place, and Mapping in Literary and Cultural Studies, NewYork: Palgrave Macmillan, 2011.pp.8-9.

[5] Jianjun Kang, Li Hou, Spatial Substitution: Interpretation of Sergei Yesenin's poetry By Hai Zi, Advances In Social Science, Education And Humantities Research, Atlantis Press, Volume 368, November 2019, pp.73-78. 